\title{
Public Awareness Regarding Oral Cancer and Its Risk Factors in Hail City, Kingdom of Saudi Arabia
}

\author{
${ }^{1}$ Yazeed S Altamimi, ${ }^{1}$ Ammar A Siddiqui, ${ }^{1}$ Moaath A Alsayegh, ${ }^{2}$ Omar S Almansour, ${ }^{2}$ Hamoud A Alanizy, \\ ${ }^{1}$ Ibrahim S Alfawzan, ${ }^{1}$ Sattam S Alshammari, ${ }^{1}$ Saif Khan
}

\begin{abstract}
Aim: The study aimed to evaluate the level of knowledge and awareness of the general population of Hail regarding oral cancer and assess their ability to identify the risk factors that may lead to oral cancer.
\end{abstract}

Materials and methods: An observational study having crosssectional design was carried out among Hail city population, Saudi Arabia. The study was conducted in November 2017. Data were gathered from 400 respondents, through survey questionnaire, with $95.5 \%$ response rate. Nonprobability, convenient sampling technique was used in this study. Saudi citizens above 15 years old were able to participate in this study.

Results: Three hundred eighty-two (382) out of 400 (95.5\%) responded to the questionnaire including $203(53.1 \%)$ male and $179(46.9 \%)$ female. One hundred eighty-two (182) (47.6\%) of the participants were aware of the disease while the rest 200 $(52.4 \%)$ of them were not. There was a significant difference between the age and the awareness of oral cancer $(p<0.001)$ and between the level of education and the awareness of oral cancer $(p<0.001)$. The respondents succeeded to identify smoking and alcohol as risk factors 328 (85.9\%), 271 (70.9\%), respectively. While only 47 (12.3\%), 20 (5.2\%), 139 (36.4\%) participants said that old age, sunlight exposure, and diet are risks factors, respectively.

Conclusion: The present study concluded that people lacked knowledge, and awareness regarding established risk factors of oral cancer. Health education related to primary prevention of oral cancer at the community and individual level needed to improve. Awareness of maintaining a healthy lifestyle which excludes the consumption of established risk factors of oral cancer was below par.

Clinical significance: Improving oral cancer awareness of the population will lead to early detection of the lesion, and this eventually will help in primary prevention and better prognosis among those who have a lesion.

Keywords: Awareness, Hail, Oral cancer, Saudi Arabia.

How to cite this article: Altamimi YS, Siddiqui AA, Alsayegh MA, Almansour OA, Alanizy HA, Alfawzan IS, AlshammariSS, Khan S. Public Awareness Regarding Oral Cancer and Its Risk Factors

\footnotetext{
${ }^{1}$ Department of Preventive Dentistry, College of Dentistry University of Hail, Hail, Kingdom of Saudi Arabia

${ }^{2}$ General Dentist, Hail, Kingdom of Saudi Arabia

Corresponding Author: Ammar A Siddiqui, Department of Preventive Dentistry, College of Dentistry, University of Hail, Hail, Kingdom of Saudi Arabia, Phone: +00966553226295, e-mail: ammarqta2002@hotmail.com, a.siddiqui@uoh.edu.sa
}

in Hail City, Kingdom of Saudi Arabia. World J Dent 2019;10(1): 41-45.

\section{Source of support: Nil}

Conflict of interest: None

\section{INTRODUCTION}

Oral cancer is considered as a significant issue in several areas around the world, in which oral and pharyngeal cancer together are taking sixth place in the most common cancer in the whole world. ${ }^{1}$

The most common malignancy of the oral cavity is squamous cell carcinoma, which usually seen as ulcerated lesion with sharp raised and hard edges along with necrotic center and hard base, rapid in growth and usually asymptomatic at early stage. ${ }^{2}$ But oral cancer has various clinical appearances in different stages and often does not reveal the signs of malignancy so may not be recognizable in an early time. ${ }^{3}$

Early diagnosis of oral cancer may reduce the mortality and morbidity associated with the disease. ${ }^{4}$ Wherefore the increasing of the awareness and understanding of populations regarding the signs and symptom of oral cancer are important as that will help and assist in the detection of the problem in an early stage. There are so many risk factors that may increase the chance for oral cancer such as tobacco, alcohol, diet, radiation, familial and genetic predisposition, immunosuppression, syphilis, and occupational risks. ${ }^{5}$ The smoking habit is existing at different ages in Saudi Arabia, and many of them have started smoking before the age of $15 .{ }^{6}$ Fruits and Vegetables especially green peppers, carrots, and fresh tomatoes were linked to a reduced risk of oral cancer while red meat, cheese, rice and so many were linked to higher risk of this cancer. Some occupations have reported a rise in the number of oral cancer cases like the jobs that require working outdoors. The exposure of ultraviolet light may lead to lip cancer and may lead to actinic cheilitis which could transform to squamous cell carcinoma. ${ }^{5}$ By avoiding what they can from the known risk factors in addition to the early detection, this type of cancer is largely preventable. In Saudi Arabia based on our review, a study in Riyadh city in 2015 was found. The study showed a lack of awareness and knowledge of the public regarding oral cancer and its risk factors. ${ }^{8}$ 
To the best of knowledge, there are no studies in Hail region about oral cancer knowledge and its awareness in Hail city, so this study was conducted to evaluate the level of knowledge and awareness of the general population regarding oral cancer and its risk factors.

\section{MATERIALS AND METHODS}

An observation study having cross-sectional design was carried out among Hail city population, Kingdom of Saudi Arabia. The study was conducted in November 2017. Data were gathered from 400 respondents with 95.5\% response rate. Nonprobability, convenient sampling technique was used in this study. Saudi citizens above 15 years old were only the inclusive criteria for this study. Written informed consent was obtained from all the participants before data collection. Faced and content validated questionnaire was in the Arabic language comprised 16 questions divided into three parts. The first part gathered the personal information as age, gender, level of education and the smoking habit. Then the second one assessed the previous general idea and knowledge about oral cancer while the last part evaluated the knowledge regarding the risk factors that could lead to oral cancer. Data were displayed as number and percentage, Chi-square test was used. The Statistical Package for the Social Sciences (SPSS) version 20 used for data entry and analysis. A $p$ value $<0.05$ was considered significant. Ethical approval was applied through the University of Hail, research and ethical approval committee and was guaranteed under an approval number H-2018-072.

\section{RESULTS}

Three hundred eighty-two (382) out of 400 (95.5\%) responded to the questionnaire including 203 (53.1\%) male and 179 (46.9\%) female. Most of the participants had a bachelor degree (43.2\%) and high school education $(40.8 \%)$. One hundred fifty-five $(40.6 \%)$ of the participants were from age 15 to 20, 42 (11\%) from age 21 to $30,87(22.8 \%)$ from age 31 to $40,79(20.7 \%)$ from age 41 to 50 and 19 (5\%) were 50 years and more. Fifty-five (14.4\%) were smokers, 23 (6\%) were ex-smokers while 304 (79.6\%) never smoked (Table 1).

\section{General Knowledge and Awareness}

The respondents answered a question whether they are aware of oral cancer and heard about it, 182 (47.6\%) of the participants were aware of the disease while the rest 200 $(52.4 \%)$ of them were not. There was a significant difference between the age and the awareness of oral cancer $(\mathrm{p}<0.001)$ and between the level of education and the awareness of oral cancer $(p<0.001)$ (Table 2$)$.
Two hundred and sixty-one (68.3\%) of them agreed that oral cancer is preventable (Graph 1) and 240 (62.8\%) of them mentioned that it is curable (Graph 2).

A question has been asked what they will do when they find a small lesion on their mouths, 116 (30.4\%) of the participants will go immediately to a dentist or a doctor, $164(42.9 \%)$ will wait sometimes as it is may disappear, but in contrast, 102 (26.7\%) will not go until they feel pain (Graph 3).

\section{Knowledge of Risk Factors}

The respondents requested to point out any of the factors that they think it could be a risk factor for oral cancer. Three hundred twenty-eight (85.9\%), 271 (70.9\%) of them succeeded to identify smoking and alcohol as risk factors, respectively. Unfortunately, they could not recognize the rest of the risk factors. Only 47 (12.3\%), 20 (5.2\%), 139 $(36.4 \%)$ said that old age, sunlight exposure, and diet are risks factors, respectively (Table 3 ).

\section{DISCUSSION}

The study aimed to evaluate the level of knowledge and awareness of the general population in Hail, regarding oral cancer and assess their ability to identify the risk factors that may lead to oral cancer. The early diagnosis of oral cancer is key to reduce mortality and morbidity associated with this disease (Baykul et al.). ${ }^{4}$ Thus it is important to measure the increase in the awareness of populations regarding oral cancer and its risk factors as this may help in early detection or even prevention of oral cancer.

Oral cancer in Saudi Arabia does appear to be low when compared to Southeast Asian countries however it is highest among the GCC (Gulf Cooperation Council) countries (Brown et al.). ${ }^{9}$

Table 1: Demographics of respondents

\begin{tabular}{lll}
\hline & & $n(\%)$ \\
\hline Gender & Male & $203(53.1)$ \\
& Female & $179(46.9)$ \\
\hline Age & $15-20$ & $155(40.6)$ \\
& $21-30$ & $42(11)$ \\
& $31-40$ & $87(22.8)$ \\
& $41-50$ & $79(20.7)$ \\
& 50 and more & $19(5)$ \\
\hline Level of education & Uneducated & $2(0.5)$ \\
& Primary & $2(0.5)$ \\
& Secondary & $50(13.1)$ \\
& High school & $156(40.8)$ \\
& Bachelor & $165(43.2)$ \\
& Postgraduate & $7(1.8)$ \\
\hline Smoking & Smoker & $55(14.4)$ \\
& Ex-smoker & $23(6)$ \\
& Never smoked & $304(79.6)$ \\
\hline
\end{tabular}


Table 2: Awareness of respondents regarding the oral cancer according age and level of education

\begin{tabular}{|c|c|c|c|c|c|}
\hline & & \multicolumn{2}{|c|}{ Are you aware of oral cancer? } & \multirow[b]{2}{*}{ Total } & \multirow[b]{2}{*}{$p$ value } \\
\hline & & Yes & No & & \\
\hline \multirow{5}{*}{ Age } & $15-20$ & $44(28.4 \%)$ & $111(71.6 \%)$ & $155(40.6 \%)$ & \multirow{5}{*}{$<0.001$} \\
\hline & $21-30$ & $17(40.5 \%)$ & $25(59.5 \%)$ & $42(11 \%)$ & \\
\hline & $31-40$ & $52(59.8 \%)$ & $35(40.2 \%)$ & $87(22.8 \%)$ & \\
\hline & $41-50$ & $57(72.2 \%)$ & $22(27.8 \%)$ & $79(20.7 \%)$ & \\
\hline & 50 and more & $12(63.2 \%)$ & $7(36.2 \%)$ & $19(4.9 \%)$ & \\
\hline Total & & $182(47.6 \%)$ & $200(52.4 \%)$ & $382(100)$ & \\
\hline \multirow{6}{*}{ Level of education } & Uneducated & $0(0 \%)$ & $2(100 \%)$ & $2(0.52 \%)$ & \multirow{6}{*}{$<0.001$} \\
\hline & Primary & $1(50 \%)$ & $1(50 \%)$ & $2(0.52 \%)$ & \\
\hline & Secondary & $8(16 \%)$ & $42(84 \%)$ & $50(13.09 \%)$ & \\
\hline & High school & $66(42.31 \%)$ & $90(57.69 \%)$ & $156(40.84 \%)$ & \\
\hline & Bachelor & $102(61.82 \%)$ & $63(38.18 \%)$ & $165(43.19 \%)$ & \\
\hline & Postgradute & $5(71.43 \%)$ & $2(28.57 \%)$ & $7(1.83 \%)$ & \\
\hline Total & & $182(47.6 \%)$ & $200(52.4 \%)$ & $382(100)$ & \\
\hline
\end{tabular}

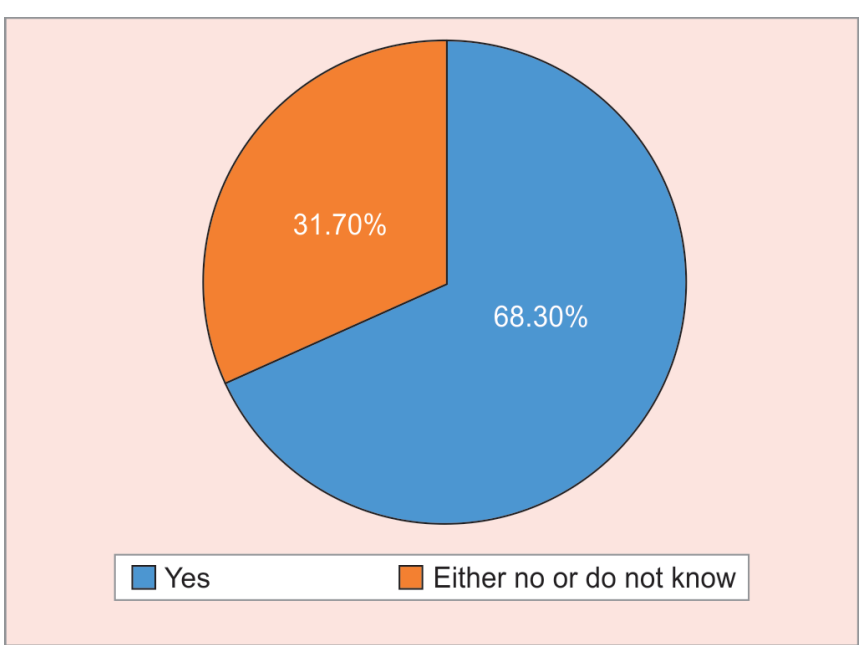

Graph 1: Respondents who think that oral cancer is preventable

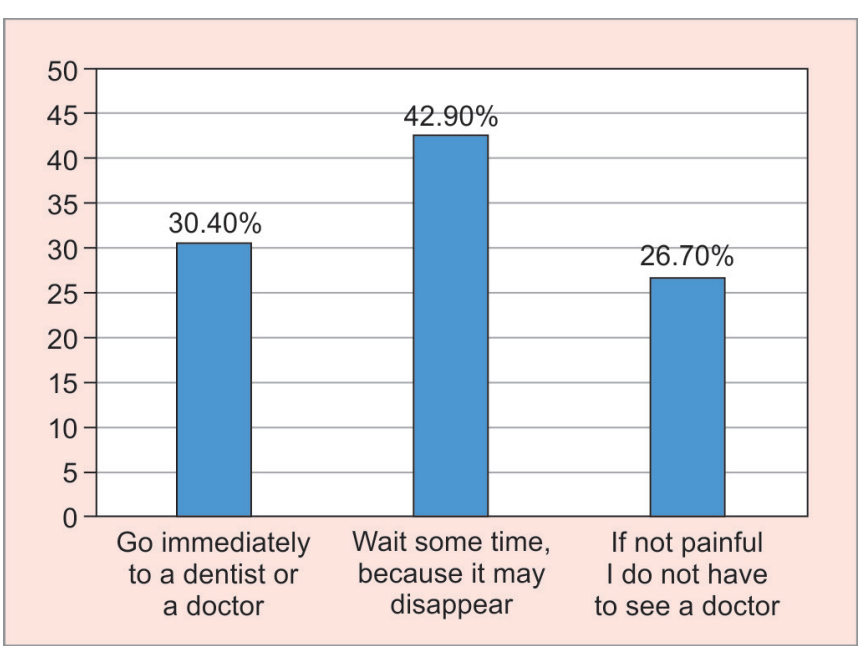

Graph 3: Action of respondents when they find a small lesion in the mouth

The present study shows that $47.6 \%$ of the participants are aware of or have heard of oral cancer previously. This is nearly the same as was found in Riyadh city by a study made in 2015 which showed that $53.6 \%$ of their participants had heard of oral cancer (Al-Maweri et al.). Another study by Formosa et al., ${ }^{10}$ in Australia revealed

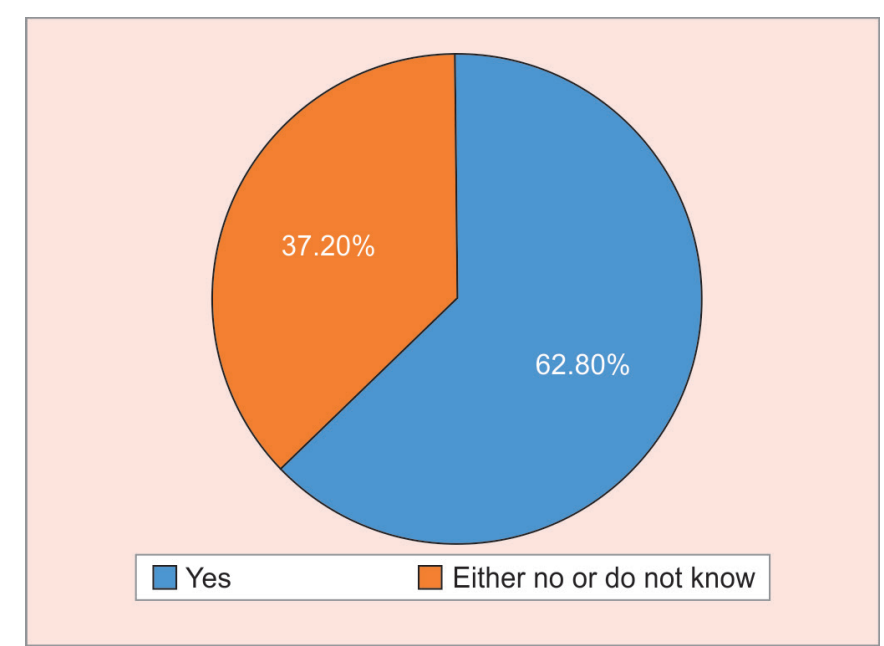

Graph 2: Respondents who think that oral cancer is curable

that $52.3 \%$ knew about oral cancer while in India which has a high rate of occurrence as it has been estimated that 83,000 cases happen every year, A study there showed that $91.2 \%$ had heard of oral cancer.

Socioeconomic factors were found to have a clear relationship with the degree of awareness of oral cancer. In our study, we found a significant difference between age and the awareness of oral cancer, and between the level of education and the awareness of oral cancer. Life experience and good education have a major role in increasing awareness of oral cancer.

Successful early diagnosis depends completely on whether the patient attends for screening examination or not. Therefore, it relies on the individual awareness to seek help (Walsh et al. 2013). ${ }^{11}$ In case a small lesion is detected in the mouth, most of the participants had a positive attitude toward going to a dentist or a doctor either immediately or wait for some days. But $26.7 \%$ of them noted that they are not planning to meet a specialist unless they feel pain.

As the prevention is always one of our targets, the individual should develop a good lifestyle behavior 
Table 3: The respondents' knowledge regarding risk factors of oral cancer

\begin{tabular}{llll}
\hline Risk factor & Yes & No & Do not know \\
\hline Smoking & $328(85.9 \%)$ & $23(6 \%)$ & $31(8.1 \%)$ \\
Alcohol & $271(70.9 \%)$ & $39(10.2 \%)$ & $72(18.8 \%)$ \\
Old age & $47(12.3 \%)$ & $227(59.4 \%)$ & $108(28.3 \%)$ \\
Sunlight exposure & $20(5.2 \%)$ & $249(65.2 \%)$ & $113(29.6 \%)$ \\
Diet & $139(36.4 \%)$ & $136(35.6 \%)$ & $107(28 \%)$ \\
\hline
\end{tabular}

particularly avoiding the risk factors that are associated to oral cancer including tobacco use, alcohol drinking, betel quid chewing, low vegetable, and fruit consumption (Petti et al.). ${ }^{12}$

Nearly, $85.9 \%, 70.9 \%$ of the respondents succeeded to identify the smoking and alcohol as one of the risk factors, respectively. Many studies around the world showed that smoking is the highest risk factor (Al-Maweri et al., Peker et al.). ${ }^{13,14}$ Although most of them identified smoking and alcohol, only $12.3 \%, 5.2 \%, 36.4 \%$ participants could recognize that old age, sunlight exposure and diet, respectively are potent risk factors which indicate lack of knowledge regarding the risk factors. Same was found by a study in Riyadh city (Warnakulasuriya et al.) ${ }^{1}$ and studies in Yemen (Al-Maweri et al.), ${ }^{13}$ Malaysia (Ghani et al., Turkey Peker et al.). ${ }^{14,15}$

\section{CONCLUSION}

The present study concluded that people of Hail lack awareness regarding oral cancer and they have inadequate knowledge of some established risk factors of oral cancer. Oral health education is needed to increase the level of awareness and creation of a supportive environment to facilitate a healthy lifestyle among the residents of Hail.

\section{Limitation of the Study}

Because of the lack of logistics and support, data were not gathered from the whole Hail region, but only from Hail city using non-probability convenient sampling technique. So the sample may not accurately represent the complete population. This can be considered as a major limitation of the present study. Other limitations may include study design bias such as respondent bias.

\section{REFERENCES}

1. Warnakulasuriya S. Global epidemiology of oral and oropharyngeal cancer. Oral oncology. 2009;45(4):309-316.

2. Silva SRd, Juliano Y, Novo NF, Weinfeld I. Comparative study of knowledge about oral cancer among undergraduate dental students. Einstein (SãoPaulo). 2016;14(3):338-345.
3. Akbari N, Raeesi V, Khazaei T, Ramezanzadeh K, Ebrahimipour S. Evaluation of General Dentists' and Dental Specialists' Knowledge about Oral Cancer in South Khorasan-Iran 2014. Asian Pacific Journal of Cancer Prevention. 2015;16(16):6987-6990.

4. Baykul T, Yilmaz H, Aydin Ü, Aydin M, Aksoy M, Yildirim D. Early diagnosis of oral cancer. Journal of International Medical Research. 2010;38(3):737-749.

5. Kumar M, Nanavati R, Modi TG, Dobariya C. Oral cancer: Etiology and risk factors: A review. Journal of Cancer Research and Therapeutics. 2016;12(2):458.

6. Bassiony MM. Smoking in Saudi Arabia. Saudi medical journal. 2009;30(7):876-881.

7. Agrawal M, Pandey S, Jain S, Maitin S. Oral cancer awareness of the general public in Gorakhpur city, India. Asian Pacific Journal of Cancer Prevention. 2012;13(10):5195-5199.

8. Al-Maweri, Sadeq Ali, Bassel Tarakji, Anas B. Alsalhani, Hashem M. Al-Shamiri, Nader Ahmed Alaizari, M. A. Altamimi, and Shourouk Darwish. "Oral cancer awareness of the general public in Saudi Arabia." Asian Pac J Cancer Prev 16, no. 8 (2015): 3377-3381.

9. Brown A, Ravichandran K, Warnakulasuriya S. The unequal burden related to the risk of oral cancer in the different regions of the Kingdom of Saudi Arabia. Community dental health. 2006 Jun 1;23(2):101.

10. Formosa J, Jenner R, Nguyen-Thi MD, Stephens C, Wilson C, Ariyawardana A. Awareness and Knowledge of Oral Cancer and Potentially Malignant Oral Disorders among Dental Patients in Far North Queensland, Australia. Asian Pacific journal of cancer prevention: APJCP. 2015;16(10):4429-4434.

11. Walsh T, Liu JL, Brocklehurst $P$, Glenny AM, Lingen $M$, Kerr AR, Ogden G, Warnakulasuriya S, Scully C. Clinical assessment to screen for the detection of oral cavity cancer and potentially malignant disorders in apparently healthy adults. Cochrane Database Syst Rev. 2013 Jan 1;11.

12. Petti S. Lifestyle risk factors for oral cancer. Oral oncology. 2009 May 31;45(4):340-350.

13. Al-Maweri SA, Addas A, Tarakji B, Abbas A, Al-Shamiri HM, Alaizari NA, Shugaa-Addin B. Public awareness and knowledge of oral cancer in Yemen. Asian Pac J Cancer Prev. 2014 Jan 1;15:10861-10865.

14. Peker I, Alkurt MT. Public awareness level of oral cancer in a group of dental patients. J Contemp Dent Pract. 2010 Mar 1;11(2):49-56.

15. Ghani WM, Doss JG, Jamaluddin M, Kamaruzaman D, Zain RB. Oral cancer awareness and its determinants among a selected Malaysian population. Asian Pacific Journal of Cancer Prevention. 2013;14(3):1957-1963. 


\section{Questionnaire on Oral Cancer Awareness}

Please choose the most appropriate answer
1. Age:
$15-20$
$\square 21-30$
$\square 31-40$
$\square 41-50$
$\square 1-60$
$\square$ More than 60
2. Gender:
$\square$ Male
$\square$ Female

3. Level of education:

$$
\text { Uneducated }
$$

$\square$ Primary

$\square$ Secondary

High school

$\square$ Bachelor

Postgraduate

4. Do you smoke?

$\square$ Yes

$\square$ Never smoked

Ex-smoker

5. Have you heard about oral cancer? $\square$ Yes $\square$ No

6. Do think that oral cancer is preventable? $\square$ Yes $\quad \square$ No $\quad \square$ I do not know

7. Do think that oral cancer is curable? $\quad \square$ Yes $\quad \square$ No $\quad \square$ I do not know

8. When you find a small lesion in your mouth, what will you do?

$\square$ Go immediately to a dentist or a doctor

Wait some time, because it may disappear

Wait until it become painful and if not painful I do not have to see a doctor

Choose among of these what you think is a risk factor of oral cancer :
Yes
No
I do not know

\section{Old age}

10. Smoking

11. Alcohol drinking

12. Sun exposure

13. Diet

14. Other risk factor :

\section{Thank you for your time}

